•综述・

\title{
虫媒传粉植物荞麦的生物学特性与研究进展
}

\author{
吴凌云 黄双全 ${ }^{*}$ \\ (华中师范大学生命科学学院进化与生态学研究所, 武汉 430079)
}

\begin{abstract}
摘要: 菾麦是禾本科之外的谷物类作物, 具有较高的营养和药用价值。栽培荞麦有甜菾(Fagopyrum esculentum)和 苦菾(F. tartaricum), 这两种一年生草本分别为自交不亲和的二型花柱、自交亲和的同型花柱植物; 前者结实依赖 昆虫传粉。根据国内外调查研究, 前人对蓼科菾麦属(Fagopyrum)记录了 30 个物种名, 已有形态学和遗传多样性的 调查表明该属的物种多样性中心位于我国西南地区, 特别是长江上游的三江并流区域; 甜菾和苦菾的起源地和祖 先物种也认为在该区域。本文在论述前人研究的基础上，指出对菾麦属的分类修订、野生种质资源的分布、种间 关系的调查、优良品种的选育亟待研究。孢粉学和考古学的证据显示在我国长江流域, 人们在4,500年前就开始种 植菾麦。菾麦可能曾经是山区人民的主粮, 为孕育长江流域文明提供了食物资源。加强对菾麦基础生物学特性的 研究, 运用现代基因组学的方法有望澄清栽培菾麦的起源并探究产量不高的原因, 挖掘和利用其经济和药用价值 的性状, 为菾麦成为一类优良的粮食作物提供参考依据。
\end{abstract}

关键词: 菾麦; 作物起源; 二型花柱; 药用价值; 长江流域; 野生种质资源; 系统发生学; 祖先种

\section{Insect-pollinated cereal buckwheats: Its biological characteristics and research progress}

Lingyun Wu, Shuangquan Huang*

Institute of Evolution and Ecology, School of Life Sciences, Central China Normal University, Wuhan 430079

\begin{abstract}
Buckwheat is a pseudo-cereal with high nutritional and officinal value, a food crop outside of Poaceae. Cultivated buckwheat includes two species: sweet or common buckwheat (Fagopyrum esculentum), a self-incompatible, distylous annual and bitter or tartary buckwheat (F. tartaricum), a self-compatible, homostylous annual herb; the former depends on insect pollination for seed production. Thirty species have been named in the genus Fagopyrum (Polygonaceae) in the world. Investigations of morphology and genetic diversity suggest that Southwest China is the diversity center of Fagopyrum, especially in the area of Three Parallel Rivers, the upper Yangtze River Valley, where ancestral species of the two buckwheat crops were originated. Previous studies of basic biology on the buckwheat crops are briefly summarized here. Future studies of the taxonomical revision on the genus Fagopyrum, collections of wild germplasm resources, exploration of the interspecific relationships and the breeding of cultivars with superior agronomic traits are strongly needed. Palynological and archaeological evidences imply that the buckwheat crop has been cultivated at least 4,500 years in the Yangtze River Valley, and might have ever been a main food for local populations in the mountain areas, providing food resource for emerging of Yangtze River civilization. Deep understanding of the basic biology of buckwheat with modern techniques of genomics could clarify the origin of cultivated buckwheat and factors limiting seed production. The buckwheat could be a superior crop in the mountain areas if the traits with high agronomic and medicinal value can be excavated and exploited.
\end{abstract}

Key words: Fagopyrum; crop origin; distyly; medicinal value; Yangtze River Valley; wild germplasm resources; phylogeny; ancestral species

菾麦是世界上广为种植的谷物类粮食作物, 因

其具有药用价值, 现在人们开发了菾麦茶、菾麦酒

收稿日期: 2017-09-09; 接受日期: 2017-12-22

基金项目: 国家自然科学基金(31030016, U1402267)

* 通讯作者 Author for correspondence. E-mail: hsq@mail.ccnu.edu.cn 
等农副产品。人们俗称的菾麦是指栽培的两个种, 即甜菾和苦菾(图1)。已有的证据表明甜养(Fagopyrum esculentum) 和苦养(F. tataricum) 是独立的两 个种，均起源于我国西南地区长江流域的上游。菾 麦是唯一不属于禾本科的、世界主要的谷物类粮食 作物; 其他谷物类是通过风媒或自花传粉, 而菾麦 则是虫媒或自花传粉。另外, 有别于其他作物, 甜 菾是二型花柱植物, 居群中有两种基因型不同的个 体(Wu et al, 2018)。中国被认为是最早栽培菾麦的 国家，而且菾麦属的大多数野生近缘物种分布在中 国。因此菾麦为我国研究栽培植物的起源、散布和 野生资源的利用、植物性系统的演化以及长江流域 文明的起源提供了一个好的研究系统。本文试图对 前人的研究工作进行小结, 提出值得深入研究的问 题，以期为我国的粮食安全、资源保护以及生态文 明建设提供参考依据。

\section{菾麦的栽培历史、种植现状及经济药用价}

对于菾麦的认识及利用, 我国自古就有诸多记 载, 如北魏贾思劦思所著的 《齐民要术》和明代李时 珍撰写的《本草纲目》。前者对菾麦的栽种技术作 了专门介绍, 后者对荞麦的药用价值进行了描述 (赵佐成等, 2007; 任长忠和赵钢，2015)。长江中下 游的孢粉证据表明早在4,500年前长江流域的南部 丘陵地区就有荞麦的种植, 这与长江地区的农耕文 化时间上相吻合 (良渚文化, 距今 5,900-4,500年) (Yi et al, 2003)。另外, 在中国的辽河流域、甘肃西 山坪发现的狍粉学证据也表明我国的菾麦文明可 能在4,500年前就开始了(Li et al, 2006, 2007; Boivin et $\mathrm{al}, 2012)$ 。在陕西省和甘肃省汉代墓葬中出土了 距今已有约2,000年的菾麦种子实物(陈贤儒，1960; 李毓芳, 1979)。自西周至春秋时期、南北朝、唐、 宋、元、明等各朝不仅记载了荞麦的种植, 还记载 了其种植技术，而真正开始大范围普及种植的时间 是在唐朝, 其后对荞麦的药用价值也有了记载, 在 明代荞麦种植技术更趋于完善(杨明君等, 2008)。这 些出土的实物、文字记载表明我国种植荞麦的历史 悠久。

菾麦在东亚及其邻近区域广为种植, 经朝鲜半 岛传入日本。公元 800 年, 菾麦在日本是一种很重要 的粮食作物(Wei, 1995)。在13-14世纪, 经西伯利亚 和俄罗斯南部传入欧洲(Gondola \& Papp, 2010)。也
有基于等位酶分析的研究认为，欧洲菾麦是从中国 北方沿着“丝绸之路”进行扩散的(Ohnishi, 1993)。据 报道，德国是欧洲最早种植菾麦的国家，随后在17 世纪，荞麦被引入比利时、法国、意大利和英国 (Wei，1995)，并由移民带入北美、阿根廷、巴西和 南非(Kreft, 2001)。在17-19世纪，菾麦在西方国家 是非常流行的食物(Cawoy et al, 2009)。据联合国粮 农组织(FAO, 2014)的统计, 全球菾麦的收获面积有 2,011,289 ha, 总产量1,924,082 t, 而且主要分布于 北温带(图2)。生产国主要有俄罗斯、中国、乌克兰、 法国、波兰、美国、巴西、哈萨克斯坦、立陶宛、 日本等(图2); 其中在中国收获面积约708,000 ha, 年产量约564,900 t, 均居世界第二。我国四川省凉 山彝族自治州具有种植苦菾的传统，常年种植面积 约有 46,666 ha, 年产量约有 $10,000 \mathrm{t}$, 苦菾是该自治 州的主要粮食作物之一, 播种面积约占所有粮食作 物种植面积的 40-50\% (赵佐成等, 2007)。由于水稻、 小麦等农作物在云贵川等高海拔地区种植困难，菾 麦可能在孕育当地文明中起着极其重要的作用。菾 麦在我国的栽培时间可能比藏族种植青稞(Hordeum vulgare Linn. var. nudum Hook. f.)更早，可能是早期 山区人们的重要粮食作物。

近年来，对菾麦理化性质、药用功效及营养价 值的研究较多。苦养产量高于甜养, 种植面积大, 是目前研究较多的物种(赵佐成等, 2007)。制成的苦 菾茶、苦养酒、苦养醋含有抗氧化、调节血糖、防 治心血管疾病等多种生物活性物质，是现代一类新 兴保健产品。菾麦制成的食品(菾麦馒头、菾麦面条 等)还具有促进消化、增强免疫力、预防癌症等作用。 临床医学观察表明，苦菾含丰富的黄酮类物质，对 糖尿病、高血压、高血脂、冠心病等疾病的治疗都 有一定的辅助作用。尤其其中的芦丁 (含量0.8-1.5\%, 其他谷物中几乎没有)可以防治因毛细血管脆弱引 起的各种出血病, 并用作高血压的辅助治疗剂(赵 佐成等, 2007; 任长忠和赵钢, 2015)。Zhang等(2017) 的研究获得了苦菾高质量(489.3 Mb)的基因组序列, 并解析了芦丁的生物合成，鉴定了芦丁生物合成途 径中编码参与代谢的酶的基因及调控这些基因表 达的转录因子, 同时注释了苦菾中存在大量可能与 植物耐铝、抗旱和耐寒相关的新基因。菾麦中含有 丰富的蛋白质，含量高达10-14.5\%，其中含有赖氨 

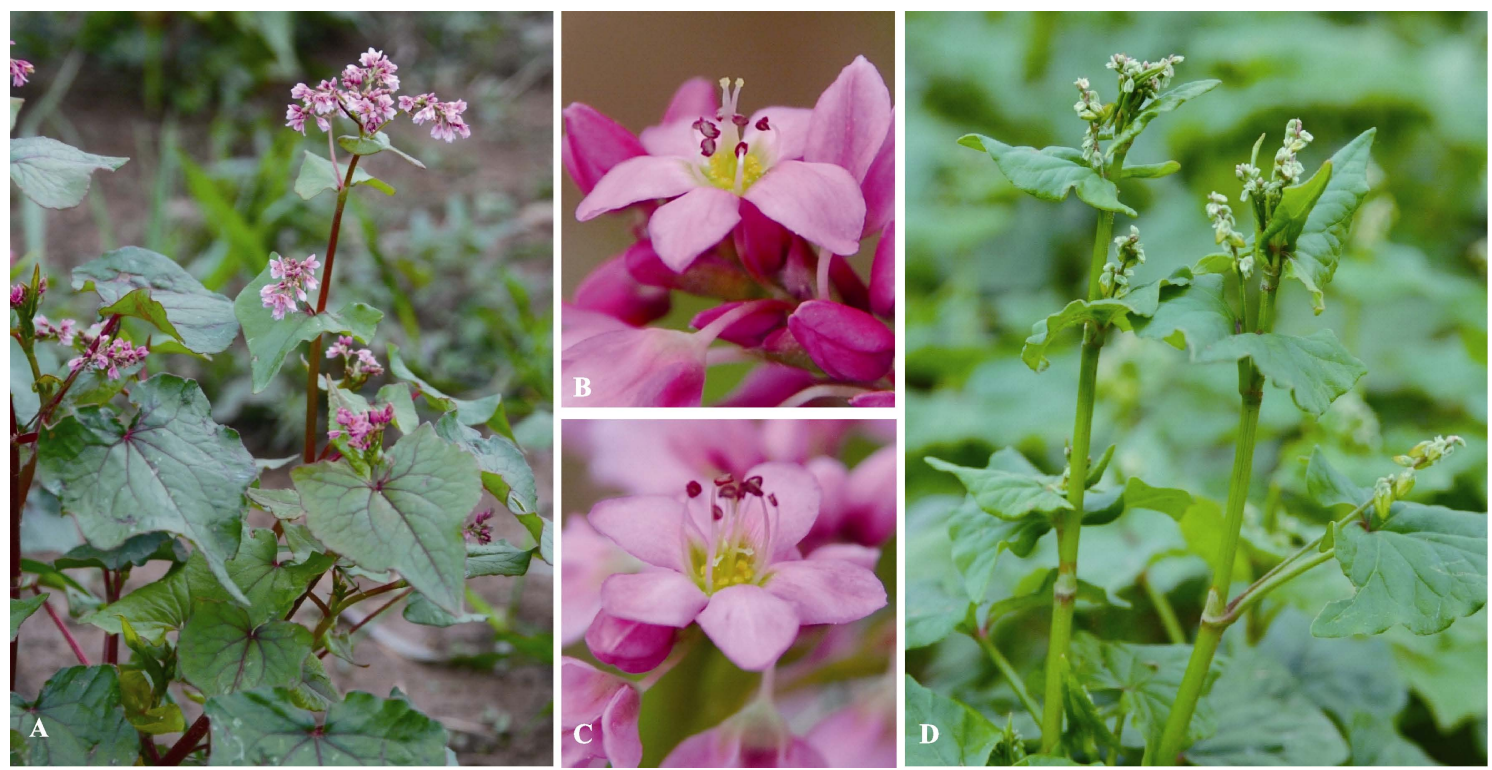

图1 栽培甜菾和苦菾的花和果实。(A)、(B)、(C)分别代表二型花柱甜菾的花序、长花柱花和短花柱花; (D)同型花柱的苦菾 正在结实。

Fig. 1 Flowers and fruits in the two cultivated buckwheat species. (A), (B) and (C) indicate flowering individuals of sweet buckwheat (Fagopyrum esculentum), a distylous crop, illustrating long-styled, and short-styled flower, respectively; (D) Fruiting individuals of bitter buckwheat (F. tartaricum), a homostylous crop.

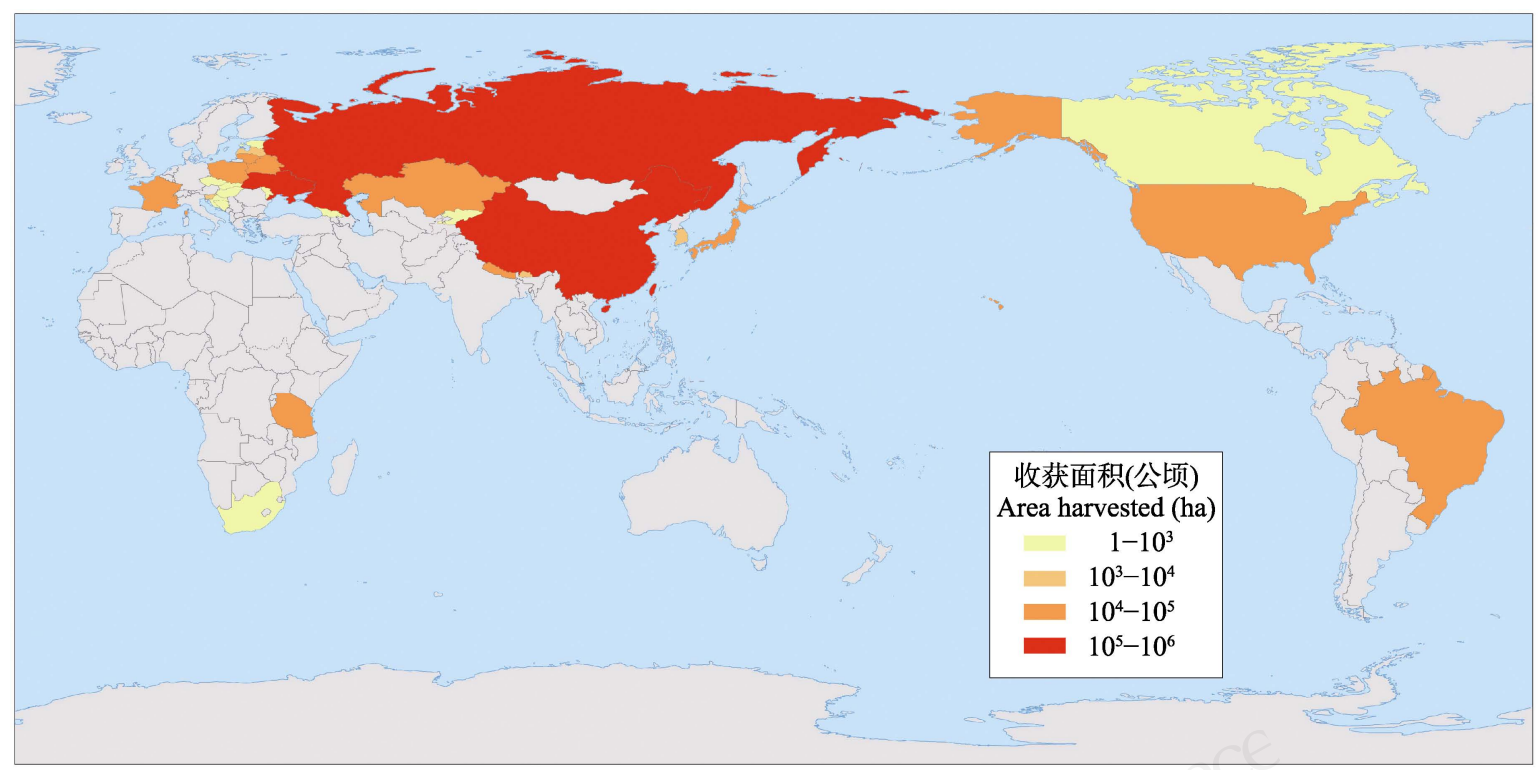

图2 世界范围内荞麦种植现状, 显示欧亚大陆普遍栽培, 数据来源于FAO (2014)。

Fig. 2 Buckwheat planting status in the world, showing the prevalence of cultivation in Eurasia, data from FAO (2014)

酸、精氨酸等氨基酸，比例适当，很容易被人体吸 收利用(赵佐成等, 2007; 任长忠和赵钢, 2015)。研 究表明, 从菾麦种子中可以分离出多种自然产生的 肽，如菾麦抗菌肽、胰蛋白酶抑制剂、抗肿瘤蛋白、 降压肽和抗氧化肽(Zhou et al, 2015)。菾麦胰蛋白酶 抑制剂除了对胰蛋白酶具有抑制作用外，还对真
菌、革兰氏阳性和革兰氏阴性菌以及多种肿瘤细胞 具有抗性(Zhou et al, 2015)。另外菾麦含有丰富的B 族维生素及维生素 $\mathrm{C} 、 \mathrm{E}$ 等参与生物体内糖、蛋白质 和脂肪代谢的重要微量有机物质, 还含有铁、锌、 铜、锰、铬、硒等人体必需的微量元素, 是一种营 养丰富的粮食作物。荞麦中脂肪的含量2.1-2.5\%, 
含有 9 种脂肪酸, 大部分为不饱和油酸和亚油酸(赵 佐成等, 2007; 陈庆富, 2012)。此外, 菾麦不同于其 他禾本科的谷物, 无麸质(gluten-free), 适合对麸质 过敏的人食用(Levent \& Bilgiçli, 2011)。

\section{养麦的分类地位、系统关系及可能的起洞}

\section{1 分类地位的归并}

菾麦是苶科菾麦属(Fagopyrum)植物, 曾隶属 于苶属(Polygonum)。林奈在《植物种志》中把菾麦 放于广义的蓼属(Polygonum sensu lato.)中; Miller于 1754 年建立菾麦属 (Fagopyrum Miller), 随后 Moench也独立建立了䒬麦属(Fagopyrum Moench)。 Meissner将菾麦各种归为蓼属中的一个组 (Fagopyrum sect. Meissn.), 随后他又认为菾麦应该 作为一个独立的属(Fagopyrum Meissn.) (陈庆富, 2012)。Gross (1913)曾试图对菾麦属进行系统的修 订，但对于莩麦属的分类地位仍有争议。Steward (1930)根据植物的形态特征, 如花序类型、托叶鞘形 状、瘦果形状等, 认为菾麦应该作为蓼属中的一个 组。菾麦属具有不同的花粉外壁纹饰(Hedberg, 1946), 其染色体基数为 8 , 而蓼属的基数为 $10 、 11$ 、 12 (Yukio，1960)，这些差别支持养麦独立成属。自 国际命名法出台后, 根据优先的原则菾麦属名统一 为Fagopyrum Miller。

《中国植物志》记载荞麦属有 15 种, 广布于亚 洲和欧洲; 其中中国有 10 种 1 变种, 有 2 种为栽培种 (甜菾和苦菾, 图1) (Li \& Hong, 2003); 至今仍不断 有新种被报道。Ohnishi (1998)报道了 4 个新种, F. pleioramosum, F. callianthum, F. capillatum和 $F$. homotropicum。Ohsako和Ohnishi (1998)报道了分布 于中国云南和四川的 2 个新种 F. macrocarpum 和 $F$. rubrifolium。Ohsako等(2002)又报道了 2 个新种 $F$. gracilipedoides和F. jinshaense。夏明忠等(2007)在中 国四川阿坝州发现了花叶野菾麦(F. polychromofolium)。刘建林等(2008a, b)报道了中国四川凉山 州2种荞麦新种皱叶野菾麦(F. crispatifolium)和密毛 野菾麦(F. densivillosum)。Tang等(2010)在四川普格 县螺䯽山发现1种新的荞麦普格野荞麦(F.pugense)。 Shao等(2011)在中国四川发现了汶川野菾麦 $(F$. wenchuanense) 和㒸彩野菾麦(F. qiangcai)。Hou等 (2015)在中国四川凉山州发现了新种螺䯽山野菾麦
(F. luojishanense)。Zhou等(2015)在中国四川甘孜藏 族自治州发现 1 种菾麦新种海螺沟野菾麦 $(F$. hailuogouense)。Wang等(2017)在中国四川普格县发 现新种龙肘山野荞麦(F. longzhoushanense)。目前在 中国报道的荞麦有 30 个种(表1)，其中部分种的性系 统、生活史和分布也已记录，但该属的分类修订亟 待开展，特别是结合DNA序列、基因组学的性状以 确认这些新命名的合法地位。

\section{2 菾麦属种间系统关系}

国内外对菾麦属内系统发生关系进行了一系 列研究, Yasui和Ohnishi (1998a，b)分别利用 $r b c L$, $a c c \mathrm{D}$ 及其之间的基因间隔区，以及ITS和 $r R N A$ 揭示 了12个种的系统关系。Ohsako和Ohnishi (2000)通过 测叶绿体基因非编码区的核苷酸序列(trnK和 $t r n \mathrm{C}$ (GCA)-rpoB), 研究了菾麦小粒组 10 个种的种内和 种间的系统演化关系。Sharma和Jana (2002)利用随 机扩增多态性DNA (random amplified polymorphic DNA，RAPD)分析了菾麦属 14 个种和 2 个亚种的系 统关系。Nishimoto等(2003)利用 2 个核基因的核苷酸 序列( $F L O / L F Y$ 和 $A G)$ 和 3 个 cpDNA ( $r b c \mathrm{~L}-a c c \mathrm{D}, \operatorname{trn\mathrm {K}}$ 和 $t r n$ C-rpoB)的片段对菾麦属小粒组系统进化关系 进行了分析。Zhou等(2014)分别利用ITS和matK构 建了 10 种荞麦的系统树，认为汶川野菾麦与金菾麦 (F. dibotrys)亲缘关系很近, 应属于大粒组。胡亚妮 等(2016)利用ITS和 ndhF-rpl32序列构建了10种荞麦 的系统树, 并分析了种间关系。Ma等(2009)概述了 研究菾麦属遗传多样性的SSR分子标记的开发, 通 过SSR标记可获得序列和多样性信息，有利于了解 遗传结构和种间关系。以上系统发生学的结果均表 明, 菾麦可以分为两组: 大粒组(cymosum)和小粒 组(urophyllum), 但是对各种间关系目前争论较大, 不同研究方法与分子标记得出的结果不全一致。目 前，甜菾、苦菾和金菾麦的叶绿体全基因组序列都 已测出(Logacheva et al, 2008; Cho et al, 2015; Yang et al, 2016), 这将为确定菾麦的种间关系奠定基础。

\section{3 栽培荞麦的起源及祖先}

关于栽培菾麦的起源地，早期1883年，De Candolle认为养麦起源于西伯利亚或中国北方(黑 龙江流域) (Matano \& Ujihara, 1979)。Steward (1930) 总结了苶族(Trib. Polygoneae)植物的分类和分布, 通过调查标本, 认为荞麦原产于中国南方。根据 Steward (1930)对中国西南野生菾麦分类与分布的 
总结, Nakao (1957)也认为栽培养麦可能起源于中 国南部。后来一系列地理分布的研究(Chen, 1999; 赵佐成等, 2007; 陈庆富, 2012; 任长忠和赵钢, 2015)表明，栽培种(甜菾和苦菾)以及 2 个野生种金 菾麦和细柄野荞麦(F. gracilipes)分布范围较广, 而 其他大多数野生菾麦主要分布在中国云南、四川、
西藏、贵州等西南地区(表1), 特别是金沙江流域野 生菾麦资源尤为丰富。近年来，多个野生新种的发 现地均在云南、四川地区(Ohnishi, 1998; Ohsako et al, 2002; Zhou et al, 2015; Tang et al, 2016)。亚洲甜 菾的等位酶分析结果表明, 中国南部居群内的变异 最大(Ohnishi，1988)。甜菾的RAPD分析也表明

表1 中国目前已发表的菾麦种类及其性系统、生活型和主要分布区

Table 1 Fagopyrum species recorded in China, with descriptions of sexual system, life form and geographic distribution

\begin{tabular}{|c|c|c|c|}
\hline $\begin{array}{l}\text { 种名 } \\
\text { Species }\end{array}$ & $\begin{array}{l}\text { 性系统 } \\
\text { Sexual system }\end{array}$ & $\begin{array}{l}\text { 生活型 } \\
\text { Life form }\end{array}$ & $\begin{array}{l}\text { 主要分布区 } \\
\text { Distribution }\end{array}$ \\
\hline \multicolumn{4}{|l|}{ 大粒组 Big-achene (cymosum) } \\
\hline 金菾麦 F. dibotrys (D. Don) Hara & 二型花柱 Distyly & 多年生 Perennial & 亚洲、欧洲、美洲等 Asia, Europe, America, etc. \\
\hline 甜养麦 F. esculentum Moench & 二型花柱 Distyly & 一年生 Annual & 亚洲、欧洲、美洲等 Asia, Europe, America, etc. \\
\hline 大野荞 F. megaspartanium Q. F. Chen & 二型花柱 Distyly & 多年生 Perennial & $\begin{array}{l}\text { 中国 (云南、西藏、贵州)等 China (Yunnan, Tibet, } \\
\text { Guizhou), etc. }\end{array}$ \\
\hline 毛野菾 F. pilus Q. F. Chen & 二型花柱 Distyly & 多年生 Perennial & 中国(云南、西藏)等 China (Yunnan, Tibet), etc. \\
\hline 汶川野养麦 F. wenchuanense J. R. Shao & 二型花柱 Distyly & 一年生 Annual & 中国(四川) China (Sichuan) \\
\hline F. homotropicum Ohnishi & 同型花柱 Homostyly & 一年生 Annual & $\begin{array}{l}\text { 中国(云南、四川、西藏)等 China (Yunnan, Sichuan, Tibet), } \\
\text { etc. }\end{array}$ \\
\hline 苦菾麦 F. tataricum (L.) Gaertn. & 同型花柱 Homostyly & 一年生 Annual & 亚洲、欧洲、美洲等 Asia, Europe, America, etc. \\
\hline 左贡野菾 F. zuogongense Q. F. Chen & 同型花柱 Homostyly & 一年生 Annual & 中国(云南、四川、西藏) China (Yunnan, Sichuan) \\
\hline \multicolumn{4}{|l|}{ 小粒组 Small-achene (urophyllum) } \\
\hline F. callianthum Ohnishi & 二型花柱 Distyly & 一年生 Annual & $\begin{array}{l}\text { 中国(云南、西藏)、不丹等 China (Yunnan, Tibet), Bhutan, } \\
\text { etc. }\end{array}$ \\
\hline F. capillatum Ohnishi & 二型花柱 Distyly & 一年生 Annual & 中国(云南)、尼泊尔等 China (Yunnan), Nepal, etc. \\
\hline 心叶野菾麦 F. gilesii (Hemsl.) Hedb. & 二型花柱 Distyly & 一年生 Annual & 中国(云南、四川、西藏) China (Yunnan, Sichuan, Tibet) \\
\hline $\begin{array}{l}\text { 纤梗野菾麦 } \\
\text { F. gracilipedoides Ohsako \& Ohnishi }\end{array}$ & 二型花柱 Distyly & 一年生 Annual & 中国(云南) China (Yunnan) \\
\hline $\begin{array}{l}\text { 金沙野菾麦 } \\
\text { F. jinshaense Ohsako \& Ohnishi }\end{array}$ & 二型花柱 Distyly & 一年生 Annual & 中国(云南) China (Yunnan) \\
\hline 小野荞麦 F. leptopodum (Diels) Hedb. & 二型花柱 Distyly & 一年生 Annual & 中国(云南、四川等) China (Yunnan, Sichuan, etc.) \\
\hline 线叶野荞麦 F. lineare (Sam.) K. Haraldson & 二型花柱 Distyly & 一年生 Annual & 中国(云南等) China (Yunnan, etc.) \\
\hline F. macrocarpum Ohsako \& Ohnishi & 二型花柱 Distyly & 一年生 Annual & 中国(四川) China (Sichuan) \\
\hline F. pleioramosum Ohnishi & 二型花柱 Distyly & 一年生 Annual & $\begin{array}{l}\text { 中国(云南、四川、西藏)、尼泊尔 China (Yunnan, Sichuan, } \\
\text { Tibet), Nepal }\end{array}$ \\
\hline 㒸彩野菾麦 F. qiangcai D. Q. Bai & 二型花柱 Distyly & 一年生 Annual & 中国(四川) China (Sichuan) \\
\hline 长柄野荞麦 F. statice (Leveille) Gross & 二型花柱 Distyly & 多年生 Perennial & 中国(云南、贵州) China (Yunnan, Guizhou) \\
\hline 硬枝野养麦 F. urophyllum Gross & 二型花柱 Distyly & 多年生 Perennial & 中国(云南、四川、甘肃) China (Yunnan, Sichuan, Gansu) \\
\hline 皱叶野养麦 F. crispatifolium J. L. Liu & 同型花柱 Homostyly & 一年生 Annual & 中国(四川) China (Sichuan) \\
\hline $\begin{array}{l}\text { 细柄野荞麦 } \\
\text { F. gracilipes (Hemsl.) Dammer }\end{array}$ & 同型花柱 Homostyly & 一年生 Annual & $\begin{array}{l}\text { 中国(云南、四川、贵州、陕西等) China (Yunnan, Sichuan, } \\
\text { Guizhou, Shaanxi, etc.) }\end{array}$ \\
\hline F. rubrifolium Ohsako \& Ohnishi & 同型花柱 Homostyly & 一年生 Annual & 中国(四川) China (Sichuan) \\
\hline 疏穗野荞麦 F. caudatum (Sam.) A. J. Li & 不确定 Unknown & 一年生 Annual & 中国(云南、四川、甘肃) China (Yunnan, Sichuan, Gansu) \\
\hline 密毛野菾麦 F. densivillosum J. L. Liu & 不确定 Unknown & 一年生 Annual & 中国(四川) China (Sichuan) \\
\hline $\begin{array}{l}\text { 海螺沟野养麦 F. hailuogouense J. R. } \\
\text { Shao, M. L. Zhou \& Q. Zhang }\end{array}$ & 不确定 Unknown & 多年生 Perennial & 中国(四川) China (Sichuan) \\
\hline $\begin{array}{l}\text { 龙肘山野养麦 } \\
\text { F. longzhoushanense J. R. Shao }\end{array}$ & 不确定 Unknown & 一年生 Annual & 中国(四川) China (Sichuan) \\
\hline 螺䯽山野菾麦 F. luojishanense J. R. Shao & 不确定 Unknown & 一年生 Annual & 中国(四川) China (Sichuan) \\
\hline $\begin{array}{l}\text { 花叶野荞麦 F. polychromofolium A. H } \\
\text { Wang J. L. Liu et P. Yang }\end{array}$ & I.不确定 Unknown & 一年生 Annual & 中国(四川) China (Sichuan) \\
\hline 普格野荞麦 F. pugense T. Yu & 不确定 Unknown & 一年生 Annual & 中国(四川) China (Sichuan) \\
\hline
\end{tabular}


中国南部的多态性比例最高, 因此研究者提出甜养 是从中国南部扩散至亚洲其他国家(Murai \& Ohnishi, 1996)。任长忠和赵钢(2015)根据瓦维洛夫的作物 起源中心学说及前人的研究, 认为云南西北部可能 是栽培苦荞的初生起源中心, 西藏东部和四川中部 与南部可能是其次生起源中心; 而野生荞麦主要分 布于云南西部和中部, 且云南西部也是苦荞的主产 区，这两个野生莽麦主要分布区可能是中国荞麦的 另一个次生起源中心。目前证据支持中国西南部是 菾麦属的分布及多样性中心, 也是其起源中心 (Ohnishi, 1995; 赵佐成等, 2007; Weisskopf \& Fuller, 2014; Tang et al, 2016)。

关于栽培甜荞与苦荞的祖先问题, 目前主要有 两种假说。早期研究者认为金菾麦是甜荞和苦菾的 祖先(Gross，1913; Steward, 1930; Hedberg, 1946; Campbell, 1976), 在形态学上金菾麦与甜菾更为接 近; 但后来分子水平(cpDNA和同工酶)的分析表明 金菾麦与苦菾的亲缘关系更近(Kishima et al, 1995; Yamane \& Ohnishi, 2001), 不支持该观点。另一观点 认为甜荞和苦荞是独立起源的, 但对于二者的祖先 种存在两种不同的观点。一是认为甜菾和苦荞的祖 先分别为野生甜菾和野生苦菾, 主要基于甜菾和苦 荞野生种的发现及其地理分布特性, 以及亲缘关系 分析。Ohnishi (1995)在中国云南发现野生甜菾(F. esculentum ssp. ancestralis)和野生苦荞(F. tataricum ssp. potanini), 且与栽培菾麦可以杂交。野生甜菾的 分布局限于云南西部和四川, 海拔1,000-1,500 m, 云南金沙江流域和四川雅狵江流域的贫㾑土壤及 岩石生境(Ohnishi, 1995, 2004), 其中长江流域上游 的三江流域(金沙江、澜沧江和怒江)是野生甜菾的 分布中心(赵佐成等, 2007; 陈庆富, 2012)。野生苦 荞分布则较为广泛, 青藏高原较寒冷地区都有分布 (Ohnishi, 1995, 2004)。甜荞与苦菾的野生祖先的分 布区域的不同, 也表明两种栽培菾麦是独立起源的 (Ohnishi, 1995; 陈庆富, 2012)。形态特征、同工酶 变异和cpDNA的RFLP (restriction fragment length polymorphism)分析表明苦菾与野生苦菾亲缘关系 很近、甜菾与野生甜菾亲缘关系很近(Ohnishi, 1995, 1998; Ohnishi \& Matsuoka, 1996)。同工酶和AFLP (amplified fragment length polymorphism)分析表明, 我国西藏东部可能是栽培甜菾起源地之一(Ohnishi, 2004)。野生苦菾与栽培苦菾的RAPD和AFLP分析
表明, 栽培苦菾可能起源于中国西藏东部或云南西 北部(Tsuji \& Ohnishi, 2000, 2001)。另一观点认为甜 菾的祖先种是大野荞(F. megaspartanium), 而苦菾 的祖先种是毛野菾(F. pilus)。Chen (1999)认为甜菾 和苦菾分别起源于中国西南部较温暖地区和青藏 高原东部海拔较高的冷凉地区。甜莽和苦菾的形态 学、细胞学、生态适应性、繁殖特点等基本特征分 别类似于大野菾和毛野菾(Chen，1999，2001; 陈庆 富, 2012)。推测毛野菾生长于不利于虫媒传粉的冷 凉气候中, 诱发了基因重组和突变, 最后进化成苦 菾。虽然目前支持甜菾和苦荞独立起源的证据较多, 但其祖先种的确定主要是日本学者在 20 世纪 90 年 代开展的; 利用新一代基因组学的方法探寻其可能 祖先类群，成为澄清这一问题的有效途径。

\section{荞麦属植物的繁殖生物学特征}

菾麦属植物是一年生或多年生草本, 少为半灌 木(硬枝野菾麦、大野荞和毛野菾) (Li \& Hong, 2003; 陈庆富，2012)。生境类型广泛，包括山坡草地、山 谷湿地、路边、农田和荒地等(Li \& Hong, 2003; 赵 佐成等，2007)。菾麦属的花序总状或伞房状，辐射 对称花两性，白色、粉色或浅绿色; 花被片5, 雄荵 有 8 枚, 排成 2 轮, 外轮 5 , 内轮 3 ; 花柱 3 , 胚珠 1 , 花 基部有蜜腺，单花寿命为 1 天。花期一般为6-9月， 果期8-10月(Li \& Hong, 2003)。栽培荞麦在我国南 方可以春秋两季播种。瘦果具3棱, 成熟后由绿色变 成灰褐色且易掉落。属的模式种为甜养(Fagopyrum esculentum Moench)。

荞麦属植物的性系统的调查显示该属有同型 花柱(homostyly)和二型花柱(distyly)物种(表1，图1), 我们最近的分析表明该属至少发生过3次从二型花 柱向同型花柱的演化(Wu et al, 2017)。二型花柱是 指同一物种的不同个体上花药高度与柱头位置交 互对应，表现出交互的雌雄异位现象; 同型花柱是 指花药柱头高度没有空间上的分离，处在同一位 置。甜菾为二型花柱的物种，同型花授粉和自交均 不亲和、长花柱花与短花柱花之间的异交授粉才能 结实。与典型的异型花柱植物类似, 甜菾长柱花的 花粉产量比短柱型高，而花粉大小比短柱型小 (Björkman，1995)。苦菾为花柱同型、自交亲和 (Nishimoto et al, 2003)。另外, 甜菾花相对较大、粉 色、花蜜量较大; 而苦菾花小、偏绿色、花蜜量小。 
据甜荞和苦荞的转录组测序的结果表明, 这些差别 可能与基因的差异性表达有关, 甜菾中与二糖代谢 相关的潜在差异表达基因相对丰富, 而葡萄糖、果 糖和蔗糖是甜菾花蜜的主要成分(Logacheva et al, 2011)。研究发现S-ELF3基因只在甜菾短柱型植株表 达, 可能是控制甜荞短柱表型的候选基因, 此基因 也可能与自交不亲和性有关(Yasui et al, 2012)。利用 构建的甜荞基因组草图作为参考序列, 通过高通量 测序标记技术，Yasui等(2016)成功确定了控制甜荞 自交不亲和的新的候选基因, 基因组数据库和基因 组草图序列可为开发具有优良农艺性状的荞麦品 种提供基础。

甜菾和苦养在生态适应性上也有差异, 甜菾适 应比较温暖的气候(最适生长温度: $18-23^{\circ} \mathrm{C}$ ), 若温 度低于 $15^{\circ} \mathrm{C}$, 开花就受到抑制, 温暖气候有利于虫 媒传粉; 而苦菾能适应比较寒冷的气候(最适生长 温度: $12-23^{\circ} \mathrm{C}$ ), 对高温比较敏感, 高温对植株生长 发育和产量不利(赵佐成等, 2007; Cawoy et al, 2009; 陈庆富, 2012)。较高温度 $\left(25^{\circ} \mathrm{C}\right.$ 以上 $)$ 会导致菾麦的 花萎蒸、种子败育、胚囊畸形以及果实干疽等 (Slawinska \& Obendorf, 2001)。菾麦自古以来就有种 植, 主要是由于它生长周期短(60-80天)、适应性强, 能有效地利用各种资源(赵佐成等, 2007; 杨明君等, 2008)。

自交不亲和的甜荞依赖传粉者传递花粉才结 实, 调查表明访花传粉昆虫是泛化的, 主要包括膜 翅目( 蜜蜂、熊蜂、独居蜂)、双翅目(食蚜蝇科、丽 蝇科等), 另外还有鳞翅目、半翅目、脉翅目等其他 昆虫(Jacquemart et al, 2007; Wu et al, 2017)。在许多 国家, 蜜蜂被认为是栽培菾麦最普遍且最主要的访 花者(Jacquemart et al, 2007)。但不同访花昆虫的传 粉效率仍需进一步研究。

\section{4 展望}

菾麦是一种很好的药食同源植物。由于荞麦果 实成熟后容易脱落的落粒特性，结实率及产量低下， 对其开发和利用的空间还很大。甜菾两型花之间授 粉才能结实, 而苦养可以自交, 但即使是人工补充 授粉, 甜菾的结实率都不到 $50 \%$, 而苦菾结实率可 达 $80 \%$ (作者未发表数据)。由于菾麦自身的生物学 特性以及其他大宗作物的发展导致荞麦播种面积 呈减少趋势, Jacquemart等(2012)质疑了菾麦是否仍
然是有前途的作物。为保障国家粮食安全, 开发新 的主粮作物被我国政府提上日程。菾麦作为一种起 源于中国的粮食作物, 与长江流域文明的发展密不 可分。但是我们目前对其生物学特性、起源地, 如 何提高菾麦产量和种植技术方面还有待深入研究, 培育出自交亲和的甜荞品种有利于提高甜菾的产 量, 从而扩大其种植范围。该属具有二型和同型花 柱物种, 为性系统演化的研究提供了好的模式系 统。我们正在同国内基因组学的同行合作, 将在近 期完成甜菾的全基因组测序, 为回答这一演化问题 和挖掘优良的农艺性状奠定基础。

目前的研究主要集中在栽培的甜菾和苦荞, 对 于我国西南丰富的野生荞麦资源研究甚少, 对于这 些野生种质资源应该加以保护和利用。据研究野生 金菾麦的根茎具有抑菌、抗炎和抗肿瘤等作用(赵佐 成等, 2007), 我们2012-2015年在四川、云南进行野 外调查时, 注意到大量野生资源遭到破坏, 有些种 群已经消失。对二型花柱植物, 种群中两种表型的 比例偏离1:1将影响有性繁殖, 加剧了地方种群的 灭绝。对于这些珍贵的资源植物的家底需要调查并 实行有效的保护措施，避免陷入濒临灭绝的境地。 对于荞麦属的分类地位及栽培菾麦的祖先种仍存 在诸多争议, 在开展野外种质资源收集的同时, 需 要厘清该属的系统发生与演化关系。

致谢：感谢赵佐成教授给予菾麦项目的指导和大 力帮助, 感谢陈家宽教授从南昌大学专项中支付 本文的出版费。

\section{参考文献}

Björkman T (1995) The effectiveness of heterostyly in preventing illegitimate pollination in dish-shaped flowers. Sex Plant Reproduction, 8, 143-146.

Boivin N, Fuller DQ, Crowther A (2012) Old World globalization and the Columbian exchange: Comparison and contrast. World Archaeology, 44, 452-469.

Campbell CG (1976) Buckwheat: Fagopyrum (Polygonaceae). In: Evolution of Crop Plants (ed. Simmonds NW), pp. 235-237. Longman, London \& New York.

Cawoy V, Ledent JF, Kinet JM, Jacquemart AL (2009) Floral biology of common buckwheat (Fagopyrum esculentum Moench). The European Journal of Plant Science and Biotechnology, 3, 1-9.

Chen QF (1999) A study of resources of Fagopyrum (Polygonaceae) native to China. Botanical Journal of the Linnean 
Society, 130, 53-64.

Chen QF (2001) Discussion on the origin of cultivated buckwheat in genus Fagopyrum (Polygonaceae). In: Proceedings of the 8th International Symposium on Buckwheat, pp. 206-213, August, Chunchon, Republic of Korea.

Chen QF (2012) Plant Sciences on Genus Fagopyrum. Science Press, Beijing. (in Chinese) [陈庆富 (2012) 菾麦属植物科 学. 科学出版社, 北京.]

Chen XR (1960) Excavation of Han Tombs in Mozuizi, Wuwei, Gansu Province. Archaeology, (9), 15-28. (in Chinese) [陈贤儒 (1960) 甘肃武威磨咀子汉墓发掘. 考古, (9), 15-28.]

Cho KS, Yun BK, Yoon YH, Hong SY, Mekapogu M, Kim KH, Yang TJ (2015) Complete chloroplast genome sequence of tartary buckwheat (Fagopyrum tataricum) and comparative analysis with common buckwheat (F. esculentum). PLoS ONE, 10, e0125332.

Food and Agriculture Organization of the United Nations (FAO) (2014) Production of Buckwheat by Countries. http://www.fao.org/home/en/ (accessed on 2017-05-13).

Gondola I, Papp PP (2010) Origin, geographical distribution and phylogenic relationships of common buckwheat (Fagopyrum esculentum Moench). Buckwheat, 2, 17-32.

Gross MH (1913) Remarques sur les Polygonées de l'Asie Orientale. Bulletin de Géographie Botanique, 23, 7-32.

Hedberg O (1946) Pollen morphology in the genus Polygonum L. (s. lat.) and its taxonomical significance. Svensk Botanisk Tidskrift, 40, 371-404.

Hou LL, Zhou ML, Zhang Q, Qi LP, Yang XB, Tang Y, Zhu XM, Shao JR (2015) Fagopyrum luojishanense, a new species of Polygonaceae from Sichuan, China. Novon, 24, 22-26.

Hu YN, Zhang ZW, Wu B, Gao J, Li YQ (2016) Genetic relationships of buckwheat species based on the sequence analysis of ITS and ndhF-rpl32. Biodiversity Science, 24, 296-303. (in Chinese with English abstract) [胡亚妮, 张宗 文, 吴斌, 高佳, 李艳琴 (2016) 基于ITS和ndhF-rpl32序 列的菾麦种间亲缘关系分析. 生物多样性, 24, 296-303.]

Jacquemart AL, Cawoy V, Kinet JM, Ledent JF, Quinet M (2012) Is buckwheat (Fagopyrum esculentum Moench) still a valuable crop today? The European Journal of Plant Science and Biotechnology, 6, 1-10.

Jacquemart AL, Gillet C, Cawoy V (2007) Floral visitors and the importance of honey bee on buckwheat (Fagopyrum esculentum Moench) in central Belgium. The Journal of Horticultural Science and Biotechnology, 82, 104-108.

Kishima Y, Ogura K, Mizukami K, Mikami T, Adachi T (1995) Chloroplast DNA analysis in buckwheat species: Phylogenetic relationships, origin of the reproductive systems and extended inverted repeats. Plant Science, 108, 173-179.

Kreft I (2001) Buckwheat research, past, present and future perspectives 20 years of internationaly coordinated research.
In: Proceedings of the 8th International Symposium on Buckwheat, pp. 361-366, August, Chunchon, Republic of Korea.

Levent H, Bilgiçli N (2011) Enrichment of gluten-free cakes with lupin (Lupinus albus L.) or buckwheat (Fagopyrum esculentum M.) flours. International Journal of Food Sciences and Nutrition, 62, 725-728.

Li AR, Hong SP (2003) Fagopyrum. http://foc.eflora.cn/ (accessed on 2017-10-02)

Li X, Dodson J, Zhou X, Zhang H, Masutomoto R (2007) Early cultivated wheat and broadening of agriculture in Neolithic China. Holocene, 17, 555-560.

Li YF (1979) Western Han Tombs in Maquan, Xianyang, Shaanxi Province. Archaeology, (2), 125-135. (in Chinese) [李毓芳 (1979) 陕西咸阳马泉西汉墓. 考古, (2), 125-135.]

Li YY, Willis KJ, Zhou LP, Cui HT (2006) The impact of ancient civilization on the northeastern Chinese landscape: Palaeoecological evidence from the Western Liaohe River Basin, Inner Mongolia. Holocene, 16, 1109-1121.

Liu JL, Tang Y, Xia MZ, Shao JR, Cai GZ, Luo Q, Sun JX (2008a) Fagopyrum crispatifolium J. L. Liu, a new species of Polygonaceae from Sichuan, China. Journal of Systematics and Evolution, 46, 929-932. (in Chinese with English abstract) [刘建林, 唐宇, 夏明忠, 邵继荣, 蔡光泽, 罗强, 孙俊秀 (2008a) 中国四川苶科菾麦属一新种— 皱叶野菾麦. 植物分类学报, 46, 929-932.]

Liu JL, Tang Y, Xia MZ, Shao JR, Cai GZ, Luo Q, Sun JX (2008b) Fagopyrum densovillosum J. L. Liu, a new species of Polygonaceae from Sichuan, China. Bulletin of Botanical Research, 28, 530-533. (in Chinese with English abstract) [刘建林, 唐宇, 夏明忠, 邵继荣, 蔡光泽, 罗强, 孙俊秀. (2008b). 中国养麦属(苶科)一新种——密毛野菾麦. 植物 研究, 28, 530-533.]

Logacheva MD, Kasianov AS, Vinogradov DV, Samigullin TH, Gelfand MS, Makeev VJ, Penin AA (2011) De novo sequencing and characterization of floral transcriptome in two species of buckwheat (Fagopyrum). BMC Genomics, 12, 30.

Logacheva MD, Samigullin TH, Dhingra A, Penin AA (2008) Comparative chloroplast genomics and phylogenetics of Fagopyrum esculentum ssp. ancestrale-a wild ancestor of cultivated buckwheat. BMC Plant Biology, 8, 59.

Ma KH, Kim NS, Lee GA, Lee SY, Lee JK, Yi JY, Park YJ, Kim TS, Gwag JG, Kwon SJ (2009) Development of SSR markers for studies of diversity in the genus Fagopyrum. Theoretical and Applied Genetics, 119, 1247-1254.

Matano T, Ujihara A (1979) Agroecological classification and geographical distribution of the common buckwheat, Fagopyrum esculentum M. in the East Asia. Japan Agricultural Research Quarterly, 13, 157-162.

Murai M, Ohnishi O (1996) Population genetics of cultivated common buckwheat, Fagopyrum esculentum Moench X. 
Diffusion routes revealed by RAPD markers. Genes \& Genetic Systems, 71, 211-218.

Nakao S (1957) Transmittance of cultivated plants through the Sino-Himalayan route. In: Peoples of Nepal Himalaya (ed. Kihara H), pp. 397-420. Fauna and Flora Research Society, Kyoto.

Nishimoto Y, Ohnishi O, Hasegawa M (2003) Topological incongruence between nuclear and chloroplast DNA trees suggesting hybridization in the urophyllum group of the genus Fagopyrum (Polygonaceae). Genes \& Genetic Systems, 78, 139-153.

Ohnishi O (1988) Population genetics of cultivated common buckwheat, Fagopyrum esculentum Moench. VII. Allozyme variability in Japan, Korea, and China. The Japanese Journal of Genetics, 63, 507-522.

Ohnishi O (1993) Population genetics of cultivated common buckwheat, Fagopyrum esculentum Moench. VIII. Local differentiation of land races in Europe and the silk road. The Japanese Journal of Genetics, 68, 303-316.

Ohnishi O (1995) Discovery of new Fagopyrum species and its implication for the studies of evolution of Fagopyrum and of the origin of cultivated buckwheat. In: Proceedings of the 6th International Symposium on Buckwheat, pp. 175-190, August, Shinshu, Japan.

Ohnishi O (1998) Search for the wild ancestor of buckwheat. I. Description of new Fagopyrum (Polygonaceae) species and their distribution in China and the Himalayan hills. Fagopyrum, 15, 18-28.

Ohnishi O (2004) On the origin of cultivated buckwheat. In: Proceedings of the 9th International Symposium on Buckwheat, pp. 18-22, August, Prague, Czech.

Ohnishi O, Matsuoka Y (1996) Search for the wild progenitor of buckwheat. II. Taxonomy of Fagopyrum (Polygonaceae) species based on morphology, isozymes and cpDNA variability. Genes \& Genetic Systems, 71, 383-390.

Ohsako T, Ohnishi O (1998) New Fagopyrum species revealed by morphological and molecular analyses. Genes \& Genetic Systems, 73, 85-94.

Ohsako T, Ohnishi O (2000) Intra- and interspecific phylogeny of wild Fagopyrum (Polygonaceae) species based on nucleotide sequences of noncoding regions in chloroplast DNA. American Journal of Botany, 87, 573-582.

Ohsako T, Yamane K, Ohnishi O (2002) Two new Fagopyrum (Polygonaceae) species, F. gracilipedoides and F. jinshaense from Yunnan, China. Genes \& Genetic Systems, 77, 399-408.

Ren CZ, Zhao G (2015) Chinese Buckwheat Science. China Agriculture Press, Beijing. (in Chinese) [任长忠, 赵钢 (2015) 中国菾麦学. 中国农业出版社, 北京.]

Shao JR, Zhou ML, Zhu XM, Wang DZ, Bai DQ (2011) Fagopyrum wenchuanense and Fagopyrum qiangcai, two new species of Polygonaceae from Sichuan, China. Novon 21, 256-261.
Sharma TR, Jana S (2002) Species relationships in Fagopyrum revealed by PCR-based DNA fingerprinting. Theoretical and Applied Genetics, 105, 306-312.

Slawinska J, Obendorf RL (2001) Buckwheat seed set in planta and during in vitro inflorescence culture: Evaluation of temperature and water deficit stress. Seed Science Research, 11, 223-233.

Steward AN (1930) The Polygoneae of Eastern Asia. Contributions from the Gray Herbarium of Harvard University, 5, 1-129.

Tang Y, Ding MQ, Tang YX, Wu YM, Shao JR, Zhou ML (2016) Germplasm resources of buckwheat in China. In: Molecular Breeding and Nutritional Aspects of Buckwheat (eds Zhou ML, Kreft I, Woo SH, Chrungoo NK, Wieslander G), pp. 13-20. Academic Press, London.

Tang Y, Zhou ML, Bai, DQ, Shao JR, Zhu XM, Wang DZ, Tang YX (2010) Fagopyrum pugense (Polygonaceae), a new species from Sichuan, China. Novon, 20, 239-242.

Tsuji K, Ohnishi O (2000) Origin of cultivated tartary buckwheat (Fagopyrum tataricum Gaertn.) revealed by RAPD analyses. Genetic Resources and Crop Evolution, 47, 431-438.

Tsuji K, Ohnishi O (2001) Phylogenetic relationships among wild and cultivated tartary buckwheat (Fagopyrum tataricum Gaert.) populations revealed by AFLP analyses. Genes \& Genetic Systems, 76, 47-52.

Wang CL, Li ZQ, Ding MQ, Tang Y, Zhu XM, Liu JL, Shao JR, Zhou ML (2017) Fagopyrum longzhoushanense, a new species of Polygonaceae from Sichuan, China. Phytotaxa, 291, 73-80.

Wei YM (1995) Buckwheat production in China. In: Proceeding of the 6th International Symposium on Buckwheat, pp. 24-29, August, Shinshu, Japan.

Weisskopf A, Fuller DQ (2014) Buckwheat: Origins and development. In: Encyclopedia of Global Archaeology (ed. Smith C), pp. 1025-1028. Springer-Verlag, New York.

Wu LY, Chang FF, Liu SJ, SW Armbruster, Huang SQ (2018) Heterostyly promotes compatible pollination in buckwheats: Comparisons of intraflower, intraplant, and interplant pollen flow in distylous and homostylous Fagopyrum. American Journal of Botany, 105, 108-116.

Wu LY, Wang B, Schoen DJ, Huang SQ (2017) Transitions from distyly to homostyly are associated with floral evolution in the buckwheat genus (Fagopyrum). American Journal of Botany, 104, 1232-1240.

Xia MZ, Wang AH, Cai GZ, Yang P, Liu JL (2007) A new variety of Fagopyrum Polygonaceae discovered in Sichuan, China-Fagopyrum polychromofolium A. H. Wang, J. L. Liu et P. Yang. Journal of Xichang College, 21, 11-13. (in Chinese with English abstract) [夏明忠, 王安虎, 蔡光泽, 杨坪，刘建林 (2007) 中国四川荞麦属(蓼科)一新种— 花叶野养麦. 西昌学院学报, 21, 11-13.]

Yamane K, Ohnishi O (2001) Phylogenetic relationships 
among natural populations of perennial buckwheat, Fagopyrum cymosum Meisn., revealed by allozyme variation. Genetic Resources and Crop Evolution, 48, 69-77.

Yang J, Lu C, Shen Q, Yan Y, Xu C, Song C (2016) The complete chloroplast genome sequence of Fagopyrum cymosum. Mitochondrial DNA Part A, 27, 2410-2411.

Yang MJ, Guo ZX, Yang Y, Chen YQ (2008) A brief history of buckwheat cultivation in China. Inner Mongolia Agricultural Science and Technology, (5), 85-86. (in Chinese) [杨明君, 郭忠贤, 杨媛, 陈有清 (2008) 我国菾麦种植简 史. 内蒙古农业科技, (5), 85-86.]

Yasui Y, Hirakawa H, Ueno M, Matsui K, Katsube-Tanaka T, Yang SJ, Aii J, Sato S, Mori M (2016) Assembly of the draft genome of buckwheat and its applications in identifying agronomically useful genes. DNA Research, 23, 215-224.

Yasui Y, Mori M, Aii J, Abe T, Matsumoto D, Sato S, Hayashi Y, Ohnishi O, Ota T (2012) S-LOCUS EARLY FLOWERING 3 is exclusively present in the genomes of short-styled buckwheat plants that exhibit heteromorphic self-incompatibility. PLoS ONE, 7, e31264.

Yasui Y, Ohnishi O (1998a) Interspecific relationships in Fagopyrum (Polygonaceae) revealed by the nucleotide sequences of the $r b c L$ and $a c c D$ genes and their intergenic region. American Journal of Botany, 85, 1134-1142.

Yasui Y, Ohnishi O (1998b) Phylogenetic relationships among Fagopyrum species revealed by the nucleotide sequences of the ITS region of the nuclear rRNA gene. Genes \& Genetic Systems, 73, 201-210.

Yi S, Saiton T, Zhao Q, Wang P (2003) Vegetation and climate changes in the Changjiang (Yangtze River) Delta, China, during the past 13,000 years inferred from pollen records. Quaternary Science Reviews, 22, 1501-1519.

Yukio D (1960) Cytological studies in Polygonum and related genera. Botanical Magazine (Tokyo), 73, 337-340.

Zhang LJ, Li XX, Ma B, Gao Q, Du HL, Han YH, Li Y, Cao YH, Qi M, Zhu YX, Lu HW, Ma MC, Liu LL, Zhou JP, Nan CH, Qin YJ, Wang J, Cui L, Liu HM, Liang CZ, Qiao ZJ (2017) The Tartary buckwheat genome provides insights into rutin biosynthesis and abiotic stress tolerance. Molecular Plant, 10, 1224-1237.

Zhao ZC, Li BG, Zhou MD (2007) Resources of Tartary Buckwheat and Related Wild Species in China. Sichuan Science and Technology Press, Chengdu. (in Chinese with English abstract) [赵佐成, 李伯刚, 周明德 (2007) 中国 苦菾及其近缘野生种资源. 四川科技出版社, 成都.]

Zhou ML, Wang CL, Wang DZ, Zheng YD, Li FL, Zhu XM, Tang YX, Shao JR, Tang Y, Wu YM (2014) Phylogenetic relationship of four new species related to southwestern Sichuan Fagopyrum based on morphological and molecular characterization. Biochemical Systematics and Ecology, 57, 403-409.

Zhou ML, Zhang Q, Zheng YD, Tang Y, Li FL, Zhu XM, Shao JR (2015) Fagopyrum hailuogouense (Polygonaceae), one new species from Sichuan, China. Novon, 24, 222-224.

Zhou X, Wen L, Li Z, Zhou Y, Chen Y, Lu Y (2015) Advance on the benefits of bioactive peptides from buckwheat. Phytochemistry Reviews, 14, 381-388.

(责任编委：卢宝荣 责任编辑：时意专) 